\title{
O Corpo como Discurso Autobiográfico
}

\author{
Vinicius Torres Machado \\ Universidade Estadual Paulista - UNESP, Brasil \\ E-mail: viniciustorresmachado@gmail.com \\ Giovanna Galisi Paiva \\ Universidade Estadual Paulista - UNESP, Brasil \\ E-mail: gi.paiva@gmail.com
}

Resumo

A afirmação do real tem sido um campo de debate nas artes da cena que trabalham com aspectos performativos. Dentre os diversos modos de se trabalhar com o real, observa-se em profusão um tipo de teatro denominado autobiográfico. Esse teatro parece ter como impulso a elaboração de traumas individuais que dialogam com questões de interesse coletivo. O presente artigo percorre brevemente os paradigmas que envolvem a discussão do gênero autobiográfico na literatura e sua transposição para o teatro. O artigo propõe que a base autorreferencial no teatro autobiográfico se afirme não apenas pelas palavras, mas também pelo corpo, que é a afirmação de uma memória física. A cicatriz torna-se o paradigma de um trauma sofrido pelo corpo e que não precisa da palavra como único intermediário artístico.
The affirmation of the real has been a field of debate in the theater that works with performative aspects. Among the different ways of working process with the real, there is a profusion of a type of theater called autobiographical. This theatre seems to have as impulse the elaboration of individual traumas which dialogues with matters of collective interest. This article briefly goes through the paradigms that involve the discussion of the autobiographical genre in literature and its transposition tooth theater. It proposes that the self-referential basis in autobiographical theater affirms not only by words but by the body, which is the affirmation of physical memory. The scar becomes the paradigm of a trauma suffered by the body which does not need a word as the only artistic intermediary. 
Instrumento de seu corpo é, também, a tua pequena razão, brinquedo da tua grande razão. 'Eu', dizes: e ufanas-te desta palavra. Mas ainda maior, no que não queres acreditar - é o teu corpo e a sua grande razão: esta não diz eu, mas faz o eu. (NIETZSCHE, 2011, p. 35).

A emergência de uma camada de real na cena contemporânea tem se constituído como um elemento de destaque dentro da teoria e da prática artística. Se no século $X X$ o que chamávamos de real (em oposição ao realismo) era um elemento estranho que invadia o tecido ficcional da cena, hoje este real parece estar incorporado na paisagem teatral. É comum nos depararmos com elementos não cotidianos e já associarmos a uma manifestação performativa.

Carol Martín (NYU), por exemplo, em seu livro "Theatre of Real" (2013), relata o caso referente ao espetáculo Is.Man, do holandês Adelhei Roosen, em que houve um problema técnico com o microfone do ator principal, fazendo com que os espectadores não pudessem ouvi-lo. Como o som falhou em um momento de clímax do espetáculo, o ator decidiu sair de maneira abrupta do palco e abandonar o teatro. O público não pôde entender se este ato era intencional ou se não passava de um erro técnico. Essa é uma situação comum na nossa experiência de fruição de um espetáculo teatral dentro da atual dissolução das fronteiras entre o real e o ficcional.

Como proposta poética o real pode se manifestar de diversas maneiras no teatro, reunindo um leque de linguagens que abrange o biodrama, o teatro documentário, o uso de site specific, as performances autobiográficas, entre outras. Uma das características das produções que envolvem o real é a tentativa de rompimento das fronteiras estabelecidas entre arte e vida, uma recusa "à domesticação e ao confinamento da arte nos espaços de produção cultural" (QUILICI, 2015, p. 142). Embora os teatros do real possam aparecer em lugares de produção cultural hegemônica (teatros e galerias, por exemplo), há um elo evidente com a longa trajetória do movimento das vanguardas do século $X X$ e nos diversos desdobramentos desde os happenings, a performance art e a criação de objetos relacionais.
Maryvonne Saison em seu livro Les théâtres $d u$ réel: pratiques de la représentation dans le théâtre contemporain (1998) é uma das principais referências no estudo dessa predileção do real à ficção, que marca a cena contemporânea. As possíveis distinções entre o real e o ficcional ainda são pesquisas em formulação dentro da teoria e da prática teatral, sendo arriscado apresentar um conceito fechado do que seriam os denominados "teatros do real". José Antonio Sanchez (2007) aponta a importância de diferenciar a busca pela realidade, que num contexto de representação não necessariamente abala a ficção, da irrupção do real, que por ser da ordem da experiência age como uma fissura no tecido ficcional. Ambas as abordagens podem coincidir no mesmo espetáculo, mas são diferentes maneiras do real estar em cena. Mesmo a irrupção do real sendo um fenômeno marcante na produção teatral atual, talvez não se possa restringi-la a um aspecto contemporâneo. A presença da vida sempre esteve em cena, às vezes escondida sob a ficção, às vezes revelada. Como aponta Erika Fischer-Lichte, "quaisquer que sejam os lugares e os momentos nos quais o teatro acontece, ele sempre se caracteriza por uma tensão entre realidade e ficção" (FISCHER-LICHTE, 2013, p. 14). Não importa o grau da ficção, o quão o espaço, o tempo e os acontecimentos representados forem distantes da realidade, a tensão estará presente.

O que é decisivo no teatro é que, independentemente da intensidade da ficção, ele comumente acontecerá no momento presente por corpos presentes. A matéria bruta do teatro é constituída da realidade física do corpo que se move em um espaço real e compartilhado. Este artigo pretende abordar a vida que entra na cena contemporânea a partir da vontade do sujeito de apresentar elementos da sua autobiografia em cena. Neste sentido, o que pretendemos questionar é a maneira como o corpo do performer carrega marcas que são a própria revelação do sujeito, para além, ou aquém, do sentido das palavras que procura utilizar para revelar sua situação.

Atualmente, a realidade do corpo e da presença ganham novos aspectos. A conjuntura de isolamen- 
to social devido à pandemia global provocada pelo vírus SARS-CoV-2 causou uma fusão do espaço íntimo com o espaço coletivo nas produções teatrais. Devido às medidas de segurança, os artistas da cena tiveram de adaptar seu formato de trabalho, que presumia o encontro presencial. Muitos artistas, como por exemplo Marat Descartes ${ }^{1}$, encenaram peças de teatro online em suas próprias casas. O que há pouco tempo poderia ser considerado uma manifestação radical de incursão do real no teatro, atualmente, tendo em vista o fechamento dos teatros em março de 2020, usar a própria casa como espaço cênico é uma das poucas maneiras de se fazer uma arte presencial. Essa espetacularização da intimidade, que vai ao encontro do real mesmo no universo virtual, faz parte também de um grande panorama que engloba inclusive a autorrepresentação nas mídias sociais.

O mecanismo da autorrepresentação está cada dia mais arraigado no nosso cotidiano. O contexto pandêmico suscitou uma forma de encontro que depende da representação que o sujeito cria para si no enquadramento da câmera frontal. Como observa Óscar Cornago (2009), a câmera constitui um novo modelo do "eu" e uma nova verdade de enunciação. A câmera frontal é sua radicalização, que permite que o sujeito filme a si mesmo criando um recorte entre ele e o fundo que escolhe. Os espaços privados invadem os espaços que outrora eram públicos e partilhados. Em uma reunião virtual, o meu rosto pode estar sendo filmado olhando para a tela do computador, criando a ilusão de que estou presente e olhando para os outros, quando na verdade posso estar olhando simplesmente para um outro site ou até mesmo para a minha própria imagem projetada na plataforma da reunião. Há um certo tipo de espelhamento do eu na imagem refletida pela webcam. Concomitantemente, o sucesso das mídias sociais baseadas no mecanismo da autorrepresentação, como o Instagram e o Twitter, aumentou o interesse do mercado em investir em

1 Espetáculo documental online $A$ Peça estreou no dia 20 de junho de 2020 pela plataforma YouTube. "pessoas reais" como estratégia de marketing ${ }^{2}$, caracterizando um interesse do nosso tempo na exposição do sujeito real. A contingência do teatro virtual dialoga com este amplo panorama, tentando inclusive destacar uma radicalidade de auto exposição do sujeito através da intimidade de sua casa. A autobiografia acaba sendo um elemento importante nessas produções, mesmo que não intencionalmente.

Para traçarmos pontos de origem do uso da autobiografia na cena contemporânea, podemos primeiramente voltar nossa atenção ao fato de que, na literatura e nas ciências humanas a partir da década de 70, houve uma irrupção de obras escritas em primeira pessoa. Esse cenário é denominado por Beatriz Sarlo (2007) como "guinada subjetiva", em que se começa a valorizar a subjetividade na narrativa de acontecimentos do passado histórico da humanidade. As obras escritas em primeira pessoa tomaram o foco dos espaços de produção do saber e das artes a partir de então. O abismo que separava a história pessoal da história mundial armazenada nas grandes enciclopédias, integraram-se em um só discurso. Esse fato é denominado por Walter Benjamin (2012) como "crise das grandes narrativas" e pode ser considerado um rompimento entre o patrimônio cultural e o compartilhamento da experiência geradora desse patrimônio. O filósofo evidencia essa afirmação a partir do silêncio dos soldados regressados da Primeira Guerra Mundial nas trincheiras:

Na época, já se podia notar que os combatentes voltavam silenciosos dos campos de batalha. Mais pobres em experiências comunicáveis, e não mais ricos. (...) Nunca houve experiências mais radicalmente 2 A esse respeito ver a pesquisa "O show do eu - a inti-
midade como espetáculo" da professora argentina Paula
Sibilia: "O Facebook inaugurou um projeto apresentado
como "o Santo Graal da publicidade", capaz de conver-
ter cada usuário da rede em um eficaz instrumento de
marketing para dezenas de companhias que vendem
produtos e serviços na internet. (...) Em alguns casos,
os próprios autores de blogs se convertem em protago-
nistas ativos de campanhas publicitárias, como aconte-
ceu com a linha de sandálias Melissa, comercializada
por uma marca brasileira." (SIBILIA, 2008, p. 21-22). 
desmentidas que a experiência estratégica pela guerra de trincheiras, a experiência econômica pela inflação, a experiência do corpo pela fome, a experiência moral pelos governantes. Uma geração que ainda fora à escola num bonde puxado por cavalos viu-se sem teto, numa paisagem diferente de tudo, exceto nas nuvens, e em cujo centro, num campo de forças de correntes e explosões destruidoras, estava o frágil e minúsculo corpo humano. (BENJAMIN, 2012, p. 124).

Para Benjamin, uma das causas da decadência da experiência é o avanço tecnológico avassalador que ocorreu no século $X X$, especialmente no que consiste nas tecnologias de guerra, que submeteram o corpo a experiências inimagináveis. Posteriormente, os traumas ocasionados pelas grandes guerras, campos de concentração, ditaduras civis-militares na América Latina entre tantos outros acontecimentos, deram tristemente vazão à consolidação das literaturas de testemunho. Tal cenário conduz a uma valorização da narrativa pessoal no que tange à preservação da memória coletiva, para que, através da afirmação da memória, atrocidades do passado não sejam repetidas. Embora no Brasil $^{3}$ ainda exista um longo caminho a ser percorrido, em geral os relatos em primeira pessoa ganham o estatuto de testemunho da história coletiva pelo fato de muitas vezes serem "a única fonte (porque não existem outras ou porque se considera que ele é o mais confiável)" (SARLO, 2007, p. 21).

O tom confessional que marca a paisagem midiática e cultural, junto ao amplo espectro das literaturas de testemunho, influenciou um novo gênero

3 No Brasil, ainda há uma tendência de certos grupos políticos buscarem ocultar os crimes cometidos no período da ditadura civil-militar. Um exemplo disso é a promulgação da Lei da Anistia em 1979, sancionada pelo último presidente da ditadura João Figueiredo, em que juridicamente foi concedido perdão aos crimes políticos durante o período da ditadura. Já em alguns países europeus, como por exemplo a Alemanha, há diversos memoriais de monumentos de denúncia das atrocidades do regime nazista, como por exemplo o "Memorial do Holocausto", fundado em 2005. Os Julgamentos de Nuremberg foram uma série de tribunais responsáveis por julgar e condenar os crimes cometidos pelos nazistas. teatral denominado teatro autobiográfico. Este tem sua raiz na teoria de Philippe Lejeune (2008), que define a autobiografia como "a narrativa retrospectiva em prosa que alguém faz de sua própria existência, quando põe a ênfase principal em sua vida individual, em particular na história de sua personalidade" (LEJEUNE, 2008, p. 14). Para Lejeune a principal característica da autobiografia é o pacto autobiográfico, que pressupõe um contrato de fidelidade entre autor e leitor, garantindo um ponto referencial que legitima o compromisso com a verdade dos acontecimentos narrados. Sendo assim, o que caracteriza essas obras não é uma questão formal, de linguagem, podendo conter desde "memórias, a biografia, o romance pessoal, o poema autobiográfico, o diário e ou autorretrato ou ensaio" (FIGUEIREDO, 2013, p. 26), mas sim o pacto de verdade que é estabelecido com o leitor. Essa é uma questão cara à Lejeune: o compromisso com a verdade é determinante, é a partir de uma valoração prioritariamente ética que qualificamos a obra. Dentro da teoria literária, a afirmação da autobiografia como um gênero gerou polêmicas. Paul de Man (1979) ${ }^{4}$, nega a autobiografia como gênero, partindo da ideia de que o "eu" da autobiografia é uma prosopopeia, um efeito de linguagem, e que provoca apenas uma ilusão referencial. Mas para Lejeune, o desejo e compromisso com a verdade é imprescindível para o campo de conhecimento e relações humanas, pois "a distinção entre a verdade e a mentira constituem a base de todas as relações sociais" (LEJEUNE, 2008, p. 104). Assim, é necessário perseguir a verdade, mesmo sabendo da impossibilidade de atingi-la em sua plenitude.

Em Fedro (2012), Sócrates conta a história egípcia do deus Thot que apresentou ao seu pai, Tamuz, deus-sol, deus da morte, a sua nova invenção: a escrita. Thot disse ao seu pai que a escrita é o remédio para a memória e a sabedoria e que ela resolveria os problemas do esquecimento. Tamuz replicou dizendo que a escrita só aumentaria o esquecimento, pois levaria os humanos a depo-

4 'Autobiography as defacement' (Autobiografia como des-figuração), publicado em 1979. 
sitarem todo seu saber em signos externos a si. Para Tamuz, o remédio se tornaria veneno. Há uma distância espacial e temporal que separa o escritor do leitor, ambos não conversam juntos na busca de uma verdade comum, a transmissão da palavra escrita não condiz com a vivacidade do presente, mas cria a ilusão de presentificação de uma figura ausente - no caso, o autor do texto. Quando essa discussão se desloca para as artes da cena, tanto na performance como no teatro, estamos diante de um novo elemento que ganha força, a presença do eu que é corpo e, a partir daí, a palavra enunciada que não está necessariamente distante do enunciador. O corpo é testemunha das palavras ou, como diz a artista Angélica Liddell, "o corpo é a única coisa que produz verdade” (LIDDELL, 2007, p. 62).

Quando não levamos em conta a verdade do corpo, acabamos perdendo a própria dimensão da autobiografia: a realidade incontestável do corpo presente, que viveu e se afetou com a experiência narrada. Como podemos levar em conta no teatro autobiográfico uma narrativa a partir do corpo que foi afetado pela experiência? Se esses espetáculos partem de experiências pessoais geradas no corpo, como ele próprio também pode ser uma chave para criação de experiências reais em cena? Para além da história pessoal, o afeto ${ }^{5}$ provocado no corpo presente do ator pelo encontro real com o público também pode ser considerado uma forma de autobiografia. E se pensarmos nas palavras, como atribuir a elas um valor cortante, no qual o corpo reaja à própria ação de sua enunciação e não seja apenas aparelho enunciador? O corpo, que faz o eu, pode ser dimensionado como o aspecto pulsante do real nas práticas cênicas autobiográficas.

O silêncio dos combatentes observado por Walter Benjamin é produto da experiência traumática vivida por esses corpos. Nesse caso, o trauma se

$5 \mathrm{O}$ conceito afeto que uso aqui parte do conceito spinozista: "Por afeto compreendo as afecções do corpo, pelas quais sua potência de agir é aumentada ou diminuída" (Ética III, Def 3). As afecções são o encontro de um corpo com o mundo ou com outros corpos, que provocam uma experiência de aumento ou diminuição de sua potência. refere ao choque das técnicas de guerra com o corpo, que impede ao indivíduo o acesso à linguagem: "é a ferida aberta na alma, ou no corpo, por acontecimentos violentos (...) que não conseguem ser elaborados simbolicamente" (GAGNEBIN, 2009, p. 110). O trauma vivido pelos sobreviventes fez com que aquilo que foi vivenciado não fosse assimilado e elaborado em palavras. Sendo assim, diante do silêncio e da incapacidade da palavra, pode-se considerar que o espaço de elaboração do trauma também está na verdade do corpo que carrega a memória da dor. Apesar de não haver palavra, havia expressão em um silêncio cortante. Na própria ferida talvez esteja a sua dimensão material de um discurso. Neste sentido, pode-se afirmar que o lugar do trauma não reside apenas nas palavras, mas também num corpo que é testemunho da história vivida.

$\mathrm{Na}$ literatura de testemunho as palavras se distanciam do corpo, isto é, a palavra percorre muitos espaços enquanto o corpo que a gerou não está mais ali. Porém, nas artes da cena, não há a mesma distância que existe na literatura. A palavra e o corpo estão fisicamente amalgamados, a narrativa não está distante do corpo que a enuncia, ela mesma é também corpo. Palavra e corpo são afetados pela iminência do acontecimento cênico. As forças do mundo deixam rastros na memória do nosso corpo, esses rastros não são necessariamente apreendidos simbolicamente, mas existem em todos nós. "O ferimento é, se possível dizer, o momento da verdade da vista" (HAN, 2019, p. 52), a ferida revela uma zona desconhecida do nosso corpo que não temos acesso, que não está à mostra, é aquilo que não conhecemos de nós mesmos. De maneira crua, é o real em sua potência, revelando em cena a irrupção do real na ficção.

\section{É possível uma história dos corpos?}

A experiência traumática que foge do domínio das palavras ameaça os limites da representação. $O$ que resta do silêncio dos soldados, no relato de Benjamin, é uma grande carga de reminiscência aprisionada no corpo. Quando o interesse é trabalhar essa experiência no teatro talvez seja necessário 
pensar uma linguagem especial, que não se traduz apenas no texto e na narração: uma forma capaz de "se estabelecer conexão com o intolerável destas situações, (...) que trabalhe justamente com os limites do dizível, e que circunscreva, de algum modo, uma experiência próxima do irrepresentável" (QUILICI, 2015 , p. 112). Tendo em vista que a autobiografia é um gênero constituído do território da literatura, propomos que ao ser aplicada para o teatro, seja desenvolvida a partir das qualidades que envolvem o que é característico da linguagem cênica: a realidade física do corpo que se movimenta em um espaço compartilhado. Assim se faz necessário atribuir um novo aspecto à palavra enunciada, que é a sua dimensão física. Artaud já afirmava a necessidade de:

[...] relacionarmos as palavras aos movimentos físicos que lhes deram origem, se 0 aspecto lógico e discursivo da palavra desaparecer sob seu aspecto físico e afetivo, isto é, se as palavras em vez de serem consideradas apenas pelo que dizem gramaticalmente falando forem ouvidas sob seu ângulo sonoro, forem percebidas como movimentos, (...) a linguagem da literatura se recomporá, se tornará viva. (ARTAUD, 2012, p. 104).

Trabalhar com essa carga do corpo que passou pela experiência, afetado pelas forças do mundo, indica um caminho para criar uma experiência de partilha com o público que não se feche na representação simbólica das palavras. No espaço do afeto existe um comum, nem que seja no toque fugidio. O teatro que pensa o ator como uma vitrine, não toca e nem permite ser tocado. Reduz o corpo à condição de "homem-carcaça"6 (Artaud) ou "homem-estojo"7 (Benjamin). Não seria o teatro um espaço

6 O homem-carcaça é uma metáfora de Artaud para o tipo de homem que sua época produz e que está "enclausurado em certos estados corporais" (QUILICI, 2015, p. 120). Para Artaud, o verdadeiro teatro visa a transformação orgânica e física do corpo humano. (ARTAUD, 2012).

7 "O homem-estojo busca o seu conforto, e a sua concha é a quintessência dele. $O$ interior da concha é o rastro revestido de veludo que ele deixou no mundo" (BENJAMIN, 2015, p. 98). para uma reconfiguração do corpo humano, como pretendia Artaud? O corpo atravessado pela experiência provoca fissuras que nos coloca ao encontro com o que está encoberto, com a verdade não dita. Um estado de vazio, uma espécie de morte necessária para que a vida possa novamente retomar o fôlego. Levando em conta o corpo não apenas como uma estrutura biológica, mas também como fruto da dinâmica social ${ }^{8}$, podemos considerar que os traumas presentes na memória do corpo não se fecham no indivíduo, mas também dizem respeito a uma responsabilidade coletiva. A fenda provocada pela experiência traumática pode ser assumida em cena como qualidade ainda não codificada, que ao ser afirmada em um corpo silencioso em um espaço de partilha, abre espaço para uma elaboração coletiva daquilo que ainda não é possível nomear.

O teatro é uma das poucas artes que não se equivale à reprodutibilidade técnica. Dessa forma, ele guarda uma espécie de experiência originária, como diz Liddell: "O teatro continua a nos colocar em contato com algo muito antigo. Eu creio que as pessoas seguem indo ao teatro com a ideia de ver o mistério. É conservada uma curiosidade infantil a respeito da surpresa" (LIDDELL apud CORNA$\mathrm{GO}, 2005$, p. 313) $)^{9}$. O teatro como espaço de criação de uma experiência liminar, de afastamento do cotidiano produtivista pode gerar novas formas de tocar, perceber e narrar o mundo. Para que o indizível, o irrepresentável do trauma, possa encontrar um caminho de passagem, onde novas formas de continuidade histórica emerjam. Para que o silêncio possa ser partilhado como experiência.

8 Antes das teses de Foucault, Deleuze e Guattari acerca do corpo, Artaud já defendia um teatro que voltasse suas forças para a construção de um novo corpo, a ideia de transformação orgânica envolve a percepção de que as bases orgânicas do corpo são afetadas pela ordem social, que são submetidas pelo poder por um controle e disciplinamento minucioso, ou, em termos foucaultianos, microfísico. (ARTAUD, 2012).

9 No original: "El teatro nos sigue poniendo en contacto con algo antiguo. (...) Yo creo que la gente sigue yendo al teatro con la idea de ver el misterio. Se conserva una curiosidad infantil con respecto a la sorpresa." 


\section{Referências}

ARTAUD, Antonin. O Teatro e seu Duplo. 3 Ed.; 1 reimpr. São Paulo: Martins Fontes, 2012.

BENJAMIN, Walter. Magia e técnica, arte e política: ensaios sobre literatura e história da cultura.Trad. Sergio Paulo Rouanet. $8^{a}$ Ed. Revista. São Paulo: Brasiliense, 2012.

Imagens do pensamento/Sobre o haxixe e outras drogas. Edição e tradução de João Barreto. 1 Ed.; 1. Reimp. Belo Horizonte: Autêntica Editora, 2015.

CORNAGO, Óscar. Atuar de Verdade. A Confissão como Estratégia Cênica.

Urdimento, setembro 2009. p. 99-111.

Políticas de lapalabra: Esteve Graset, CarIos Marquerie, Sara Molina, Angélica Liddell. Madrid: Fundamentos, 2005.

FIGUEIREDO, Eurídice. Mulheres ao espelho: autobiografia, ficção, autoficção. Rio de Janeiro: EdUERJ, 2013.

FISCHER-LICHTE, Erika. Realidade e ficção no teatro contemporâneo. Sala Preta, v. 13, n. 2, p. 14-32, 15 dez. 2013.

GAGNEBIN, Jeanne Marie. Lembrar escrever esquecer. São Paulo: Editora 34, 2009.

HAN, Byung-Chul. A salvação do belo. 1 ed. Petrópolis: Editora Vozes, 2019.

LEJEUNE, Philippe. O pacto autobiográfico: de Rousseau à Internet. Belo Horizonte: Editora UFMG, 2008.

LIDDELL, Angélica. Perro Muerto en Tintorería: Los fuertes. Madrid: CDN, 2007.
MARTIN, Carol. Theatre of the Real. New York: Palgrave Macmillan, 2013.

NIETZSCHE, Friedrich. Assim Falou Zaratustra: um livro para todos e para ninguém. São Paulo: Companhia das Letras, 2011.

PLATÃO. Fedro (ou do belo). Tradução, apresentação e notas Edson Bini. São Paulo: EDIPRO, 2012.

QUILICI, Cassiano Sydow. O ator-performer e as poéticas de transformação de si. São Paulo: Annablume, 2015.

SÁNCHEZ, José Antonio. Prácticas de lo Real en la Escena Contemporánea. Madrid: VisorLibros, 2007.

SARLO, Beatriz. Tempo pasado: cultura da memoria e guiñada subjetiva. Belo Horizonte: UFMG, 2007.

SIBILIA, Paula. O show do eu: a intimidade como espetáculo. Rio de Janeiro: Nova Fronteira, 2008.

Recebido: 29/11/2020

Aceito: $16 / 03 / 2021$

Aprovado para publicação: 13/04/2021

Este é um artigo de acesso aberto distribuído sob os termos de uma Licença Crea- tive Commons Atribuição 4.0 Internacional. Disponível em: <http://creativecommons.org/licenses/by/4.0>.

This is an open-access article distributed under the terms of the Creative Commons Attribution License 4.0 International. Available at: $<$ http://creativecommons.org/licenses/by/4.0>.

Ce texte en libre accès est placé sous licence Creative Commons Attribution 4.0 International. Disponible sur: <http://creativecommons.org/licenses/by/4.0>. 